\title{
Attention, Awareness, Instruction, and L2 Reading Textual Input: A Personal Pronouns Study
}

\author{
Nívia Maria Assunção Costa \\ Institute of Education, Science, and Technology of Goias (IFG-câmpus Valparaíso), Valparaiso of Goias, Brazil; \\ University of Brasília (UnB), Brasília, Brazil
}

\begin{abstract}
The role of attention and the effects of potential conscious in L2 reading textual input have been a significant factor accounting for English as a Second Language Acquisition. This is a master thesis study whose three purposes were (1) to explore the central role of noticing to personal pronouns in a learner's L2 reading textual input in English; (2) to verify the effect of formal and planned instruction; and (3) to identify levels of awareness in acquisition of personal pronouns. Fifty Brazilian learners with basic level of English as an L2 were attended this experimental study. Data were collected through two different groups - control group (without instruction) and experimental group (with instruction), four phases (a pre-test, an explicit instructional phase, an immediate post-test, and a delayed pos-test phase), and three versions of written protocols (crossword puzzle, multiple-choice recognition test, and fill-in-the-blank written production test) simultaneously conducting verbalized thoughts aloud protocols. This study found that both groups had better use of the grammatical accuracy. The experimental group showed partial superior results during the reading of textual input in English as an L2 language. Also, the results showed positive correlations between the levels of metalinguistic awareness of learners.
\end{abstract}

Keywords: attention and awareness, form-focused instruction, L2 readind textual input, personal pronouns

\section{Introduction}

To say that English as a Second Language Acquisition (SLA) is a complex process is evidently trite in Brazil's education context. But complexity means that there are so many interrelated information in Second Language (L2) which briefly accounts for the Brazilian learner's attention and awareness to the reading textual input in English as an L2 (Assunção Costa, 2013). Challenges have driven Brazil's educational researchers to yield a number of insights into L2 comprehension, production, and teaching, including the role of attention and the effects of potential conscious in the target language development. As a result of this, this position stirred considerable debate was the especially purpose of this study.

In Schmidt's (1990) proposal of his noticing hypothesis, he suggests the existence of a central role for attention and levels of awareness to a linguistic factor in a learner's input, who has focused control attention to something or some things which involve the difficulty experienced in trying to reduce and control the flow of

Nívia Maria Assunção Costa, professor, Institute of Education, Science, and Technology of Goias (IFG-câmpus Valparaíso); Ph.D. student, School of Linguistic, University of Brasília; under the guidance of Ph.D. professor Cibele Brandão (PPGL/UnB). 
information at the same time. It is known that many learners are consciously involved in the linguistic elements of the target language, to extent that levels of awareness demand a specific condition to focus on meaning (Assunção Costa, 2013). As mentioned in the previous argument, the L2 development implies widespread and pervasive cognitive changes (Leow, 1997). Adopting changes means that learners are strategies in their L2 learning because they need to become aware of their own control attention to the target language input, specifically while reading. This study firstly investigates the role of attention and the effects of potential conscious in English as an L2 reading textual input. The research also verifies the effects of formal and planned instruction (Ellis, 2001) to metalinguistic awareness of the use of personal pronouns. As well, this investigation is based on Leow (1997) about what constitutes awareness, and also measures different levels of awareness in relation to Schmidt (1990). Then, this study reveals the statistical results about Brazilian learners' better use of the grammatical accuracy during the reading of textual input in English as an L2. This study intends to answer the following research questions: (1) What are the role of attention and its potential effects of awareness, and which awareness levels could promote the learning of formal aspects - the personal pronouns - while reading a textual input and testing? (2) Could the explicit instruction, through grammatical treatment, contribute to the metalinguistic awareness of the personal pronouns during textual reading in the experimental group? (3) What cognitive changes should be shown on the personal pronouns in the three types of tests - pre-test, immediate test, and post-test? and (4) Is there a statistically significant correlation between the levels of participants' awareness in two groups — control and experimental—-throughout the experiment?

\section{Brief Review of Literature}

The learning of new language can be involved into distinct levels of awareness (Assunção Costa, 2013; Leow, 1997; Schmidt, 1990). And attention, as well, despite being a factor of interest for many areas of linguistics, applied linguistic, and psychology is problematic because of the difficulty of defining that construct (Assunção Costa, 2013). For some it is a mental control to notice a linguistic and specific element in a learner's input (Schmidt, 1990). As Leow (1997) and Assunção Costa (2013) indicated, the term "attention" and its possible "levels of awareness" account for the fact that learner's ability to convert input into intake, especially input during instruction and testing when learner's cognitive processes of noticing can be accessed online/concurrent protocols (e.g., think-alouds) and offline/non-concurrent protocols (e.g., pre-test and post-test) in Second Language Acquisition (SLA). Bergsleithner (2007), as well, explains that when we say that we are not paying attention to specific linguistic features in input; it means that we are not conscious about that.

From Schmidt's perspective, the learner's paying attention to specific features in the early stage of language input is an issue highly underscored in the Noticing Hypothesis (Schmidt, 1990), a theoretical model that postulates a central role for focal attention, stemming from awareness, in order for a student to focus language input. On the other hand, focusing on instruction, both Ellis (2001) and Assunção Costa (2013) appointed out that formal instruction in a communicative and interaction output has been beneficial to leaner's conscious raising. Also Schmidt (1990) affirmed that instruction may play a relevant role in priming learners to focus linguistic elements.

As well the case with instruction topic, the debate over requisite levels of awareness in SLA throughout the frequency of input, which due to repeated instruction, a linguistic item will be noticed and integrated into the 
learner's cognitive processes, as appointed by Assunção Costa (2013) and Schmidt (1990). As a result of this, according to Assunção Costa (2013), Leow (1997), and Schmidt (1990), task demands, which refer to instructional task, are also a relevant way to a learner's ability to notice particular features that are necessary in order to accomplish that task.

\section{Brief Overview of Schmidt's (1990) Proposal: Noticing Hypothesis}

The Noticing Hypothesis was proposed in 1990 by Richard Schmidt. The Noticing Hypothesis has been encouraged scholars to consider the proposal of his noticing hypothesis in order for a student to notice language input. In this vein, for learning to occur, noticing (i.e., attention and a low level of awareness) is necessary. It would be appropriate to explain that understanding (i.e., high level of awareness) is not required.

As Schmidt (1995, p. 29) appointed out that noticing is related to "conscious registration of the concurrence of some event", and understanding is a kind of "recognition of a general principle, rule, or pattern". Furthermore, Leow (1997) showed that noticing and different levels of awareness are positive while reading text and testing a specific linguistic element. According to Schmidt (1995), conscious attention shows different levels of cognition: perception, noticing, and understanding. The first cognitive construction, perception, involves mental events from external ambient. The second one, noticing, is a necessary controlled mental process as a condition for L2 acquisition. And the last cognitive construction, understanding, is an aspect that learner can reflect about language and recognize the use of language.

Based on this idea, Leow (1997) focused on probing into the noticing function and the role of awareness in 28 learners of Spanish as an L2. Leow employed concurrent data elicitation procedures (e.g., think-aloud protocols) produced by those adult students, who were required to complete tasks designed to targeted forms. As a result of this, he found three levels of awareness: cognitive change, meta-awareness, and morphological rule formation, throughout three conditions of the participants: did not provide information about their subjective experience nor did verbalize any target rules; provided information about their subjective experience, but did not verbalize any target rules; and, provided both a report and verbalization of target rules. The results showed the presence of effects of awareness in some participants and a better use of tasks in other participants, who demonstrated noticing as a level of understanding of the targeted rules (aware) significantly better than students who evidenced noticing only (unaware).

In this context, the present study will examine the effect of different types of attention to personal pronouns while reading comprehension and testing in a population of Brazilian high school students.

\section{Method}

This study is an exploratory instead of totally conclusive study. Think aloud protocols and three versions of tasks were conducted in order to acquire responses that were transcribed for data analysis. The rationale for the protocols and versions of tasks during each test phases (pre-test, immediate test, and post-test phase) was to gather information relating to four major research questions: (1) What is the role of attention and its potential effects of awareness, and which awareness levels could promote the learning of formal aspects- the personal pronouns - while reading a textual input and testing? (2) Could the explicit instruction, through grammatical treatment, contribute to the metalinguistic awareness of the personal pronouns during textual reading in the experimental group? (3) What cognitive changes should be shown on the personal pronouns in the three types 
of test phases - pre-test, immediate test, and post-test? and (4) Is there a statistically significant correlation between the levels of participants' awareness in two groups - control and experimental — throughout the experiment?

\section{Data Collection}

Data collection included scheduled phases included four phases and two classrooms of elementary knowledge of English. One of the elementary knowledge of English was conducted with an explicit instruction, in which the experimental group received Form-Focused Instruction. The other classroom received an implicit instruction, which was conducted to a control group. The aim of the instructional phase was to prepare participants to use the personal pronouns in the immediate and delayed post-test phases. Fifty Brazilian learners of English as an L2 of a public school attended this experimental study. They were divided into two groups: control group (implicit instruction with 25 participants) and one experimental group (explicit instruction with 25 participants). The present study was designed of four phases: (1) a pre-test phase, which was designed to detect attention level, measure intake of the participants, and also verify different levels of awareness; (2) an explicit and implicit instructions; (3) an immediate post-test phase, which occurred right after the instruction; and (4) a delayed post-test phase that took place two weeks after the instruction. Both post-tests aimed at detecting attention level, measuring intake of the participants, and also verifying different levels of awareness, at two occasions after the treatment of instruction. Data were collected through verbalized thoughts aloud protocols (thin-aloud protocols) simultaneously conducting three versions of written protocols, which are crossword puzzle, multiple-choice recognition test, and fill-in-the-blank written production test. The instructional phase and the verbalized thoughts protocols were conducted in Portuguese language and when necessary in English, but the three versions of written protocols were in English. Each think-aloud protocol was audio taped and transcribed verbatim in Portuguese, and when necessary in English, translated into Portuguese by the researcher.

\section{Results}

Results from the current study (Assunção Costa, 2013) offer a framework for understanding four major research questions: (1) What is the role of attention and its potential effects of awareness, and which awareness levels could promote the learning of formal aspects - the personal pronouns - while reading a textual input and testing? (2) Could the explicit instruction, through grammatical treatment, contribute to the metalinguistic awareness of the personal pronouns during textual reading in the experimental group? (3) What cognitive changes should be shown on the personal pronouns in the three types of tests - pre-test, immediate test, and post-test? and (4) Is there a statistically significant correlation between the levels of participants' awareness in two groups - control and experimental - throughout the experiment? As Table 1 shows, the descriptive statistics indicate the results from Assunção Costa (2013) study, based on Leow (1997), about test phases and written protocol tasks:

Test phases: PT (pre-test), IT (immediate test), and DT (post/delayed-test), which are based on performances in textual reading about Personal Pronouns (\%) and levels of awareness (c) about metalinguistic reflections, which are divided into six types of category departed from zero score to 2.5 scores:

Category A: The participants did not provide any report about their subjective experiences, they did not verbalize any metalinguistic rules, and did not use any personal pronouns rule in the task (without any score); 
Category Ai: The participants did not provide any report about their subjective experiences, they verbalized any metalinguistic rules, and used any personal pronouns rule in the task ( 0.5 score);

Category B: The participants reported about their subjective experiences, they did not verbalize any metalinguistic rules, and did not use any personal pronouns rule in the task (1.0 score);

Category Bi: The participants reported about their subjective experiences, they did not verbalize any metalinguistic rules, but they used any personal pronouns rule in the task (1.5 score);

Category C: The participants reported about their subjective experiences, they verbalized any metalinguistic rules, but did not use any personal pronouns rule in the task (2 scores);

Category $\mathrm{Ci}$ : The participants reported about their subjective experiences, they verbalized any metalinguistic rules, and used the personal pronouns rule in the task (2.5 scores).

Three versions of written protocol tasks during each test phases: crossword puzzle task (1), multiple-choice recognition task (2), and fill-in-the-blank written production task (3), as regards Table 1.

Table 1

Descriptive Statistics for the Variables of the Study: Attention, Consciousness, Instruction, and Textual Reading by 50 Participants From Experimental and Control Groups

\begin{tabular}{|c|c|c|c|c|c|c|c|c|c|c|}
\hline \multirow{2}{*}{$\begin{array}{l}\text { Test } \\
\text { phases }\end{array}$} & \multicolumn{5}{|c|}{ Control group } & \multicolumn{5}{|c|}{ Experimental group } \\
\hline & $\mathrm{N}$ & Minimum & Maximum & Mean & $\begin{array}{l}\text { Standard } \\
\text { deviation }\end{array}$ & $\mathrm{N}$ & Minimum & Maximum & Mean & $\begin{array}{l}\text { Standard } \\
\text { deviation }\end{array}$ \\
\hline PT1\% & 25 & 0,00 & 50,00 & 18,86 & 16,61 & 25 & 7,14 & 57,14 & 26,00 & 12,86 \\
\hline РT2\% & 25 & 10,00 & 50,00 & 28,00 & 11,18 & 25 & 10,00 & 50,00 & 27,60 & 10,12 \\
\hline РT3\% & 25 & 0,00 & 70,00 & 39,60 & 18,37 & 25 & 0,00 & 80,00 & 38,40 & 22,11 \\
\hline TI1\% & 25 & 8,33 & 91,67 & 39,67 & 24,33 & 25 & 0,00 & 83,33 & 48,00 & 22,86 \\
\hline TI $2 \%$ & 25 & 0,00 & 90,00 & 48,00 & 21,21 & 25 & 10,00 & 90,00 & 48,40 & 19,93 \\
\hline TI3\% & 25 & 10,00 & 90,00 & 49,20 & 20,60 & 25 & 20,00 & 80,00 & 53,60 & 18,68 \\
\hline TT1\% & 25 & 0,00 & 78,57 & 33,43 & 23,75 & 25 & 14,29 & 78,57 & 43,43 & 19,33 \\
\hline ТT2\% & 25 & 0,00 & 70,00 & 40,40 & 19,89 & 25 & 10,00 & 80,00 & 42,80 & 20,31 \\
\hline TT3\% & 25 & 10,00 & 80,00 & 44,80 & 18,51 & 25 & 20,00 & 60,00 & 38,80 & 12,69 \\
\hline cPT1 & 25 & 0,00 & 17,00 & 8,22 & 6,55 & 25 & 1,50 & 18,00 & 11,28 & 4,45 \\
\hline cPT2 & 25 & 1,00 & 12,50 & 9,46 & 3,26 & 25 & 1,50 & 12,50 & 10,72 & 2,38 \\
\hline cPT3 & 25 & 0,00 & 13,00 & 8,72 & 4,26 & 25 & 1,50 & 14,00 & 11,28 & 2,30 \\
\hline cTI1 & 25 & 4,00 & 26,50 & 12,48 & 5,49 & 25 & 0,00 & 18,00 & 13,02 & 4,06 \\
\hline cTI2 & 25 & 10,00 & 18,50 & 12,42 & 1,74 & 25 & 8,50 & 16,00 & 12,46 & 1,72 \\
\hline cTI3 & 25 & 0,00 & 21,50 & 10,92 & 4,26 & 25 & 5,00 & 19,00 & 12,74 & 2,55 \\
\hline cTT1 & 25 & 1,00 & 20,50 & 13,12 & 5,58 & 25 & 0,00 & 19,50 & 14,20 & 4,88 \\
\hline cTT2 & 25 & 8,50 & 14,50 & 11,74 & 1,44 & 25 & 2,00 & 14,00 & 11,62 & 2,26 \\
\hline cTT3 & 25 & 5,00 & 14,00 & 11,98 & 1,67 & 25 & 5,50 & 13,50 & 11,56 & 1,74 \\
\hline
\end{tabular}

As a result from that descriptive statistics in Table 1, the study offers the following framework for understanding the four major research questions, which are:

\section{The Role of Attention and the Potential Effects of Awareness to the Personal Pronouns}

The results showed that, for both groups, there was evidence of statically significant values.

The results from the data collected appointed that the control group showed a better performance in grammatical accuracy for crossword and recognition written tests (two versions of task) during all the experiment 
phases, but for fill-in-the-blank written production test, a statistically significant difference was just revealed in pre-test and in the immediate post-test phases. It implies that the participants from the control group demonstrated level of noticing, showing that not only attention dispensed to the information, but also the implicit instruction and the frequency of a rich input in personal pronouns were mutually beneficial to that group.

The results about the experimental group showed a better performance was significantly reached in the four phases while the participants from that group were performing the three versions of written protocols, showing that not only level of noticing as well as explicit instruction was beneficial to that group. However, during the performing the fill-in-the-blank written production test, the levels of noticing were statistically significant in the immediate and post-test phases. It implies that the participants from that group demonstrated difficulties to achieve higher levels of awareness and also suggested that the participants may have demonstrated higher levels of awareness for both types of tests crossword puzzle and multiple-choice recognition test.

\section{The Explicit and Implicit Instruction, and the Contribution to the Metalinguistic Awareness}

Although there were statistically significant differences in performance on grammatical accuracy and metalinguistic awareness levels in both groups, the results revealed certain superiority in the experimental group compared to the control group. The results showed that the difference of both groups was not statistically significant for the type of explicit instruction received by experimental or implicit instruction by control group, since both groups had similar average partially showing thus certain homogeneity. It implies that the participants have benefited by the frequency of the input and the rich textual input in the personal pronouns, which could simply draw the attention of the participants.

\section{Cognitive Changes in the Three Types of Tests}

The results revealed the existence of different levels of consciousness metalinguistic statistically significant. And that for the control group, these kinds of awareness levels are shown in the comparison between the three types written protocols during the phases of the present experimental study. For the experimental group, such metalinguistic levels of consciousness depended on the type of test (i.e., while for the statistically significant values multiple-choice recognition test is shown throughout the phases of the present study, the crossword puzzle test showed statistically significant values only the comparison between levels of awareness in both pre-test and post-test; and for the fill-in-the-blank written production test, significant values were shown only in comparison between levels of awareness in both immediate and post tests.

\section{The Statistically Significant Correlation Between the Levels of Participants' Awareness}

The results revealed the existence of statistically significant correlation between the levels of consciousness when they were analysed by Spearman correlation. Therefore, the hypothesis was confirmed, since the performance of the participants for the personal pronouns resulted in the association analysis between metalinguistic awareness levels and better utilization of the grammatical accuracy by the participants. It implied the possibility that these participants have had to draw from a lower level of consciousness attention to higher and different levels of metalinguistic awareness in textual reading. These results corroborate the Leow (1997) argument by stating that in some participants there is better use of these levels of awareness in the post-test as a result of the facilitator role of consciousness awareness, which can provide better later retrieval of specific grammatical form. 


\section{Policy Recommendations}

The study offers glimpses of how teachers could perceive and implement tasks in favour of attention and the levels of awareness to some specific input element in the classroom. The data showed that both experimental and control groups improved their performance under conditions of attention and awareness-raising. Some even suggest that attention and levels of awareness should be required for the processes of learning, which can help students enhance language skills, as well as develop textual understanding and appreciation (Schmidt, 1990; Leow, 1997; Ellis, 2001; Assunção Costa, 2013). In view of the findings of this study, two policy recommendations are provided to improve the performance of the language learners: the kind of instruction and input demands under conditions of attention and awareness-raising.

\section{Conclusion}

This article has presented a concise overview of the theoretical and methodological topics surrounding the role of attention and its potential effects of levels of awareness in Second Language Acquisition (SLA), and provided a brief report of a current empirical study (Assunção Costa, 2013) on attention and textual reading input that have employed data were collected through verbalized thoughts aloud protocols (thin-aloud protocols) simultaneously conducting three versions of written protocols, which are crossword puzzle, multiple-choice recognition test, and fill-in-the-blank written production test. The overall findings appear to speak in favor of a complex relationship between conscious attention and grammatical accuracy in reading in the English as an L2. As well, paying attention to the targeted form tends to produce better results in levels of awareness. As Leow (1997) pointed out, a combination of protocols would help us to a more data analysis of noticing. As Schmidt (1990) said, providing opportunity to the L2 learner for focusing attention while doing something else results in deeper levels of awareness.

\section{References}

Assunção Costa, N. M. (2013). Atenção, consciência, instrução e leitura de input textual em L2: um estudo com os pronomes pessoais (Attention, awareness, instruction, and L2 reading textual input: A personal pronouns study) (M.A. thesis, Departamento de Línguas Estrangeiras e Tradução, Programa de Pós-Graduação em Linguística Aplicada, Universidade de Brasília). Retrieved from http://repositorio.unb.br/handle/10482/15046

Bergsleithner, J. M. (2007). Working memory capacity, noticing, and L2 speech production (Doctoral dissertation, Centro de Comunicação e Expressão, Programa de Pós-Graduação em Letras/Inglês e Literatura Correspondente, Universidade Federal de Santa Catarina). Retrieved from https://repositorio.ufsc.br/xmlui/handle/123456789/90089

Ellis, R. (2001). Investigating form-focused instruction. Language Learning, 51, 1-46.

Leow, R. P. (1997). Attention, awareness, and foreign language behavior. Language Learning, 47(3), 467-505.

Schmidt, R. (1990). The role of consciousness in second language learning. Applied Linguistics, 11, 129-158.

Schmidt, R. (1995). Consciousness and foreign language learning: A tutorial on attention and awareness in learning. In R. Schmidt (Ed.), Attention and awareness in foreign language learning (pp. 1-63). Honolulu, HI: University of Hawaii, National Foreign Language Resource Center. 